\title{
Framed messages effects on readmissions
}

\author{
Angela P. Halpin*1, Felicia S. Hodge ${ }^{2}$ \\ ${ }^{1}$ University of California, Irvine, United States \\ ${ }^{2}$ University of California, Los Angeles, United States
}

\author{
Received: May 1, 2016 \\ Accepted: May 31, $2016 \quad$ Online Published: June 3, 2016 \\ DOI: $10.5430 /$ jha.v5n4p95 \\ URL: http://dx.doi.org/10.5430/jha.v5n4p95
}

\begin{abstract}
Objective: As the eighth leading cause of death in the US, pneumonia (PN) is relevant to the health of the elderly and young. Accountability for readmission is part of the Affordable Care Act's Hospital Readmissions Reduction Program (RRP), which levies penalties for readmissions. We examined communication using framing effects which can motivate patients' decisions collaboratively with providers for post discharge care and readmissions prevention. Communication strategies (CS) can facilitate decision-making (DM) about health care choices. The project's aims were to (1) compare CS of framing effects (positive or negative messages) on the readmission outcome 30 days post discharge; (2) assess PN readmissions decrease 30 days post discharge when CS include the patient/family in decisions about transitions; (3) determine the impact of between patients and HCPs agreement for post hospital care, and (4) examine confounding effects between framing effects and readmission rates of age, PN severity index (PSI), and the number of diagnoses.

Methods: A double-blind randomized control trial (RCT) used parallel assignment of 153 PN patients to one of three arms to test the communication framing effects using power analysis, odds ratio, Fischer's exact and ANOVA. Arm A was the Intervention positive framing group $(n=44)$, arm B was the Intervention Negative framing group $(n=65)$, and arm $C$ was the control group ( $n$ $=44)$.

Conclusions: Findings suggest that framed messages aid in the reduction of PN readmission rates in hospitals. DM strategies incorporates education and understanding of risk by the patient, so the healthcare teams can encourage and improve readmission outcomes.
\end{abstract}

Key Words: Hospital readmission, Pneumonia, Framed messages

\section{INTRODUCTION}

Pneumonia (PN) readmissions are a concern for hospitals and healthcare providers. Readmission rates were reported at 18.5 percent of all U.S. admissions in 2012, resulting in national measures that penalize hospitals with high rates of readmission. ${ }^{[1-3]}$ Accountability for readmission is part of the Affordable Care Act's Hospital Readmissions Reduction Program (RRP), which levies financial penalties for readmissions. PN readmissions increase mortality and morbidity and the communication methods proposed become a significant opportunity in reducing such risk. ${ }^{[4]}$

When providers engage in purposeful communication using framing effects, it can motivate patients to make decisions for care post discharge, improve outcomes, and prevent readmissions. ${ }^{[5]}$ Since patients often have an imprecise assessment of the risk of the illness, the framed messages provide clarity and new information to help individuals in decision-making (DM). ${ }^{[6]}$ Therefore, patients may be able to determine the best approach for post-hospital care based on their interpreted meanings of shared information about an illness. ${ }^{[7-9]}$

\footnotetext{
* Correspondence: Angela P. Halpin; Email: ahalpin@uci.edu; Address: University of California, Irvine, 101 The City Drive, Orange, California, 92868, United States.
} 
Central to reducing readmission rates is patient involvement because patients can interpret framed messages and filter out others, which allows them to agree or disagree with recommendations by providers. ${ }^{[10]}$ Framing effects as a method of reducing readmission have not been tested in the condition of PN and the process of making decisions for care post discharge.

Framed message reference points are influenced by a patient's past history, knowledge of the specific illness, and communications with HCPs about the event's severity. ${ }^{[11,12]}$ Mortality or readmission from PN is a risk often left unspoken with patients. As a result, there is uncertainty around the risk of illness for both providers and patients. ${ }^{[13,14]}$ Perceptions of risk are influenced by comorbidities and sociocultural factors, and are a result of the meanings attributed to the individual's choices around conditions presented in negative or positive messages. ${ }^{[14]}$ Nursing therapeutic interventions are needed to provide adequate communication with patients and families to reduce negative outcomes. ${ }^{[15,16]}$ Health care providers (HCPs) must know which message frame is beneficial and the approach to apply in order to achieve successful outcomes.

Communication by HCPs using framing effects is a method to motivate patients to change behaviors, choices, and agreements. ${ }^{[10,17]}$ This research postulated that deliberate implementation of team communication strategies (CS, framing effects) with patients lowers the rates of readmission. The study provided a model for communication within the interdisciplinary team, of which the patient and family are members.

\section{MethodS}

A double-blind randomized control trial (RCT) with parallel assignment of $\mathrm{PN}$ patients $(\mathrm{N}=153)$ allocated patients to receive either one of two framed message interventions, or a controlled message. Criteria for inclusion were: (1) PN diagnosis on admission, (2) ability to understand and speak English, (3) > 55 years of age, (4) willingness to sign a consent, (5) able to hear voices or music using head phones, (6) alert and oriented, and (7) mini mental state exam (MMSE) $>26$ score. Exclusion criteria were patients with: (1) self-report of diagnosis of dementia or are known to be on a dementia medication, (2) having known hearing loss without corrective devices, and (3) PN patients with a history of being admitted in the last 60 days prior (see Figure 1). ${ }^{[18]}$

\subsection{Settings}

Data were collected from two hospitals in Southern California (HL1 and HL2) within a 13-month period (November
2013-December 2014). Recruitment began after the UCLA and the two hospitals provided Protection of Human Subject's Institutional Review Board (IRB) approval.

\subsection{Experimental intervention}

Health instruction compact disc (CD). An audio CD was used to communicate a positive or negative message to patients about the severity of their PN risk for readmission. Positive or negative framing messages were given to those in arm A and arm B; a neutral message on the outcome of readmission was provided to arm $\mathrm{C}$ (the control group). Administration of the $\mathrm{CD}$ audio interventions occurred when patients reported that they were feeling better prior to discharge.

\subsubsection{Positive message framing}

This message is important for you to listen to, we want you to have good health. As you know you have been diagnosed with $\mathrm{PN}$ - a respiratory infection. It takes time and a careful program of treatment to recover from PN. The recommended treatment following your hospital stay was designed by your health team with your input and preferences in mind. If you follow the recommendations, you are likely to:

(1) Have more energy, (2) Breathe better, (3) Experience less fatigue, (4) Have a better appetite, (5) Be able to perform more of your usual activities, (6) Prolong your life.

You are likely to experience major health benefits if you take your medications and follow up with an appointment with your doctor.

\subsubsection{Negative message framing}

This message is important for you to listen to, we want you to avoid poor health. As you know you have been diagnosed with $\mathrm{PN}$ - a respiratory infection. It takes time and a careful program of treatment to recover from PN. The recommended treatment following your hospital stay was designed by your health team with your input and preferences in mind. If you don't follow the recommendations, you are likely to:

(1) Have less energy, (2) Breathe with more difficulty, (3) Experience more fatigue, (4) Have a poorer appetite, (5) Not be able to perform as many of your usual activities, (6) Shorten your life.

You are likely to experience major health problems if you do not take your medications or follow up with an appointment with your doctor.

\subsubsection{Intervention procedure}

Patients were randomly assigned into intervention arm A or intervention arm B (framing effects), or arm C control (control group) groups by a schematic of computerized numbers. The CDs were assigned the randomized number to intervention $\mathrm{A}$, intervention $\mathrm{B}$, or control $\mathrm{C}$ groups using the same 
procedure. ${ }^{[19]}$ The patients listened to the CD message and the research associates (RA) administering the interventions followed the study protocols. The assignments were blinded; patients and research team members did not know in which arm the intervention had been assigned.

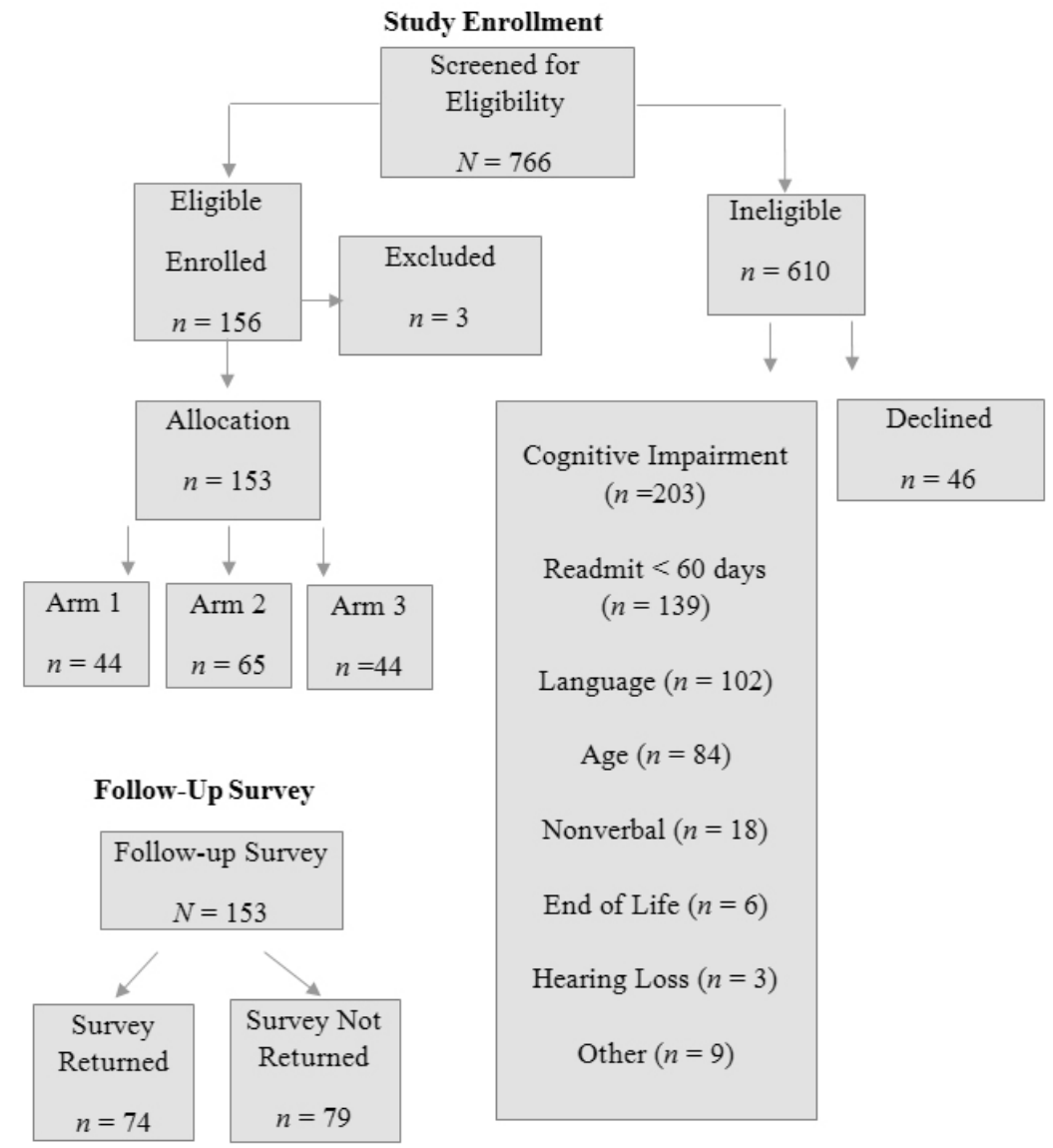

Figure 1. Study enrollment and follow-up study (1) Excluded potential may/may not have received the intervention, died, or were found to be ineligible after EMR review; (2) Ineligible potential participants did not meet all of the IRB-approved criteria for study participation; (3) Eligible potential participants met all of the IRB-approved criteria for study participation at the time of enrollment

\subsection{Data collection}

After IRB approval, patient screenings and completion of the baseline interview, eligible patients were enrolled by oral consent (waiver of signed consent). MMSE was used in screening for eligibility. MMSE was developed in 1975 and is a tool often used to screen for dementia in study subjects. ${ }^{[20,21]}$ All patients were screened for cognitive dysfunction prior to enrollment.

A medical record abstraction form was utilized to gather the patient characteristics, collected were gender, age, employment, social support, smokers, living situation, education levels, and insurance. ${ }^{[22]}$ Other variables measured were the hospital departments, PN severity index (PSI) variables, re-admission rates at 30 days, and patient mortality. Patient comorbidities, PN diagnostic test-laboratory and radiology findings were collected as part the PSI measures. Functional status, length of stay, and PSI scores were collected using questions from standard valid and reliable tools available and documentation by specialists. ${ }^{[11,23]}$
The PSI was applied using the inter-relationship of prognostic variables and comorbidities in a predictive rule. Severity and mortality are the two main concepts of the PSI prediction rule instrument. ${ }^{[24]}$ Severity is described as the likelihood of mortality within 30 days post admission to an acute care hospital. ${ }^{[23,24]}$ The PSI is reliably used in hospital screening and is a valid tool approved by the American Thoracic Society to determine the risk of mortality and outcomes. ${ }^{[1]}$

A follow up survey questionnaire was mailed to patients' home at 30 days post discharge. Questions were asked regarding patients' perceptions of breathlessness (yes/no), feelings of satisfaction with their health (yes/no), and if they had seen a physician at follow up appointment(s) (yes/no). These were followed by valid and reliable questions from the health assessment questionnaire (HAQ) that assesses satisfaction of their health. ${ }^{[25]}$ An additional question asks "How satisfied are you with your health now?" The last question inquired about the services the patients had received, if any, at home post-hospital. According to Bruce and Fries (2003), the HAQ self-administered questionnaire has content validity 
and has been used several times since 1980 in chronic illness to assess dimensions of disease-specific illness and measure outcomes in populations. ${ }^{[25]}$

\subsection{Statistical analysis}

Data were analyzed using IBM SPSS 22.0 and SAS software. ${ }^{[26-28]}$ Statistical methods included power analysis, general descriptive ANOVA, chi-square, Fisher's Exact and logistic regression models. Binary outcome variables were created to distinguish findings of independent variable or interventions on readmission rates. The independent variable was the communication strategy (framing effects), and the dependent variable was the readmission. Continuous variables were analyzed using summary statistics of means, standard deviation, median, minimum, maximum ranges, and analysis of variance tests (ANOVA) for hypothesis testing. Odds ratios (OR) applied measured predictions of likely readmits.

\subsubsection{Hypotheses}

The hypotheses measured readmission rate (dependent variable /outcome) among patient groups. Evaluation included differences in outcomes among the patient groups and compared rates of case management agreement (CMA) on readmission outcomes based on messages. Age, number of diagnoses and the severity index's effects on readmission of the PN patients were measured.

\subsubsection{Calculations}

For hypotheses 1-3, a Fisher's exact/chi-square test was performed. Using $\mathrm{G}^{*}$ Power with an alpha $=0.05$, power $=0.8$, a two-tailed test with an expected effect size being between small (0.1) and medium (0.3), this produced a necessary total sample size between 132-1,178 (132 is the sample size needed for a medium effect size and 1178 for a small effect size).

\section{RESULTS}

\subsection{Demographic characteristics}

Seven-hundred, sixty-six patients were screened; 156 were eligible and were enrolled and three patients were excluded due to death and inability to participate. The study characteristics were balanced in distribution, therefore were not confounding. All patients were between 55 and 99 years of age, with a mean age of 72.5. Diagnoses included ICD-9-codes 038.9, 486 through 495 and included community-acquired PN (CAP), aspiration PN (Asp), atypical PN, sepsis with $\mathrm{PN}$, and other or rule out PNs. Patients were admitted with a single diagnosis of PN in 92 percent of the cases; all patients were discharged with the diagnosis of PN and with secondary diagnoses. There were no statistical differences in the distribution of the diagnosis of PN across study arms $(p=.835)$.

\subsection{Experimental groups}

Readmission rates for the interventions groups were not statistically significant (see Table 1). This may mean there is no real significance, or there is some confounding variable that is potentially masking a difference.

Table 1. Comparison readmission rates (dependent variable 30)

\begin{tabular}{lllc}
\hline Source & Readmittance Rate & 95\% CI for Rate & p-value $^{\dagger}$ \\
\hline RS & $15.0 \%(23 / 153)$ & $(9.8-21.7)$ & .440 \\
HL1 & $23.2 \%(36 / 155)$ & $(16.8-30.7)$ & .056 \\
HL2 & $19.0 \%(17 / 89)$ & $(11.5-28.8)$ & .672 \\
California 2013 Annual Report & $17.4 \%$ & NA & \\
\hline
\end{tabular}

${ }^{\varepsilon}$ Confidence interval is based on Clopper-Pearson (exact method); ${ }^{\dagger} P$-value based on a one sample normal approximation test of the University Hospital readmittance rate compared to the California 2013 Annual Report readmittance rate (a test of the null hypothesis that the readmittance rate is equal to $17.4 \%$ ); RS: research study; HL: acute care hospital level

Table 2. Readmittance rate paired comparisons (dependent variable 30 )

\begin{tabular}{lll}
\hline Readmittance Rate & & $\boldsymbol{p}_{\text {-value }}^{\S}$ \\
\hline Positive Message & Negative Message & \\
$20.5 \%(9 / 44)$ & $13.9 \%(9 / 65)$ & .434 \\
Any Message & No Message (Control) & \\
$16.5 \%(18 / 109)$ & $11.4 \%(5 / 44)$ & .618 \\
\hline
\end{tabular}

${ }_{\S}^{\S} P$-value based on Fisher's Exact Test

Readmission rates for the interventions groups report 20.5 percent in the positive message group and 13.9 percent in the negative message group. This was not a statistically significant difference, hence, there was no difference between the message groups in readmission rates by the 30-day postdischarge time point $(p=.434)$. Bivariate findings indicated of those readmitted, 47.1 percent were in the positive group compared to 52.9 percent in the negative group. Again, there was no statistically significant association between a positive or negative message and readmission at 30 days (chi-square test $p=.643)$ (see Table 2).

Readmission rate for the intervention group including both messages is reported to be 16.5 percent compared with 11.4 
percent in the control group. This finding is not a statistically significant difference, hence, there is no difference between the intervention group and the control group in readmission rates by the 30-day post-discharge time point ( $p=.618$ ). In this study, negative messages had less readmission than positive messages, while no message had the lowest.

The rate of CMA by study arm is shown in Table 3. Agree- ment between the case manager and the patient regarding the transition plan is 80-85 percent in the two intervention arms and 50 percent in the control arm. A Fisher Exact Test of the results show that there is a statistically significant difference in the proportion of agreement by intervention groups at $p=.017$ for the test of independence in the distribution of agreement rate among the study arms.

Table 3. CMA by study arm

\begin{tabular}{llllll}
\hline Characteristic & Positive $(\boldsymbol{n}=\mathbf{4 4})$ & Negative $(\boldsymbol{n}=\mathbf{6 5})$ & Control $(\boldsymbol{n}=\mathbf{4 4})$ All Subjects $(\boldsymbol{N}=\mathbf{1 5 3})^{p \text {-value }}{ }^{\S}$ & $116(76)$ & .017 \\
Yes & $35(80)$ & $55(85)$ & $26(60)$ & $36(24)$ \\
No & $9(20)$ & $10(15)$ & $17(40)$ & 0 & \\
NA & 1 & 0 & 0 & 0 \\
\hline
\end{tabular}

${ }^{\S} P$-value based on Fisher's Exact Test

The analysis strategy for the assessment of influencing variables on readmission started with a practical selection of variables suggested by study design, the literature and careful thought; these included all study arms, age, comorbidities, and PN severity index (PSI). Variables were examined using Fisher Exact Test for categorical variables and odds ratios (ORs) for binary variables. Of these variables, age group and comorbidities had associations with readmission that were either statistically significant at $p \leq .05$ or had marginally significant findings $p \leq .100$. These findings are reported below.

Key predictor variables identified among the comorbidities were congestive heart failure (CHF), coronary artery disease (CAD), and hypertension (HTN), with ORs between 2.2 and 2.6, indicating patients were at least twice as likely to be readmitted having had a comorbidity, and that patients with three or more of any comorbidities at admission were 3.4 times more likely to be readmitted by 30 days post-discharge per odds ratio. Of variables, age group and most readmitted patients were in the oldest age group: $70 \%$ in the $75+$ years age group and 30\% in the 55-64 years age group were found to be significant $(p<.001)$ by Fisher's Exact Test. PSI class ranks ranged from 1-5 with the largest group (40\%) in rank 4. The study populations had a high acuity of illness and comorbidities.

\subsection{Cost savings and clinical significance}

A test of proportions indicated that the readmission rate 15 percent, was significantly lower than the reported rates from participating hospitals HL1, 23.2\% and HL 2, 19.1 percent ( $p$-values for both are $p<.001$ ). Research study (RS, study intervention) readmission rate was (15\%), in a comparison using a one-sample binomial test of the comparison hospital rates, and assumed the value was fixed with no variability.
As findings indicated there might be some beneficial effect with the use of framed messages. This population had no variability using an economic statistic binomial exact test. However, a much larger sample size would be needed to detect such a beneficial effect.

An analysis of daily total cost of a PN patient, using university health cost guidelines, provided average daily direct cost for a ventilator/high flow and non-ventilator patient hospital day. Direct costs consist of fixed-labor, supplies, and benefits. Indirect costs are fixed non-revenue expenses and include facility, supplies, and utilities. Therefore, if hospitals add the framed message to their strategies, it is assumed that a cost savings would be gained because of possible reduced readmission. However, leadership would need to buy-in to the benefits. Since consistent communication amongst providers are shown to decrease readmission rates. Pilot projects thus are suggested within hospitals' selected departments for adoption in practice.

\section{Discussion}

Effective communication is a valuable tool that can improve the exchanges between patients and HCPs. To our knowledge, this is one of the first study's using framed messages as an intervention to reduce readmission of $\mathrm{PN}$ patients. Patients must make many decisions related to care choices and follow-up actions they undertake following a stay in a hospital. Communication about their illness and its care during the transition process from illness to wellness can make a difference. It is known that communication that involves patients/families in DM can improve outcomes. Prospect theory's decision under risk (framed messages) requires further research in acute care settings (ACS) and with medical/surgical patients of various age groups. ${ }^{[10,29]}$ Therapeutic communication that clearly influences decision behaviors 
of patients/families using framed messages at the time of discharge is recommended. ${ }^{[15,16,30]}$ When framed messages are utilized at the time of transition in ACS, readmission reduction rates are influenced. This study's findings indicated negative messages were more effective in the study's older age groups because reference points and comorbidities were higher. As indicated in the literature, this group has more reference points with advanced age and because of their health profile. ${ }^{[31,32]}$

In relation to readmission, when patients hear structured messages, some patients' natural response is to turn away or to not acknowledge the framed message. This may be considered to be an "ostrich effect" or a purposeful ignoring of the message information due to fear or disbelief of the message. ${ }^{[33]}$ Secondly, dosage effects may increase the motivation of patients' favorable readmission outcomes and response to a framed message, but this too must be tested in research with this population. ${ }^{[34]}$

In trying to reduce readmission, hospitals already use multifactorial approaches such as transition options, decisions, and others. ${ }^{[35]}$ Our study is an additional method to reduce readmissions. One important factor in determining readmission is the patient's condition of illness. Contributing factors can be comorbidities, types of organisms, age, and the level of participation of the patient permitted in DM regarding his/her discharge. For this study, the findings of the disposition at the time of discharge indicate that patients with the highest readmission rates had gone home without services; 43 percent (10/23) returned to the hospital from home, and 30 percent (7/23) were readmitted from nursing homes. These findings are notable for suggesting methods to reduce readmission. For example, the interdisciplinary team can seek agreement for services at the time of discharge, even if the patient is going to his/her own home.

Discharge processes are implemented by registered nurses (RNs), case managers (CMs), and other providers in order to assist patients in understanding their choices post hospital. However, with these providers' patients are the most important part of the equation for preventing readmission and the health team can improve healthy responses to illness by using framed messages. A main point in strategies to reduce readmissions is buy-in for partnerships at each level of the chain within organizations regarding communication methods that include family/patient participation in choices at the time of discharge. Even with the healthcare transformations occurring more is to be done; as many make assumptions on family/patient support and the interventions necessary to prevent readmissions or the families/patients understanding of the post hospital care needed for rehabilitation. Although, many discharge care plans are built into algorithms by care per disease or surgeries, patients' response to illness is a unique phenomenon. Nursing and medical scholars have added a communication strategy known as message framing to the transition phenomenon, and this framing can be a significant factor in improving the outcomes of care. ${ }^{[10,36]}$ Poor management of the transition from hospital to home results in a greater incidence of readmissions to hospitals and increased hospital costs. ${ }^{[32,33,37]}$ Other adverse effects for hospitals include loss of government funds, and most important, the cost to the health of the patient and subsequent impact on family, friends, and other caregivers. ${ }^{[1-3]}$

\section{Conclusions}

This study demonstrated framed communications based on reference points of loss or gain affect behaviour-based on the findings and is consistent with previous studies, ${ }^{[10,34,35,38]}$ thus, suggesting that using framed messages and facilitating patients' participation in DM by inclusion as part of the health team makes a difference in reducing chances of readmission. However, strategies must continue to be tested for utility and effectiveness with patients who have high readmissions. Therefore, synopses of framing effects research are seen as useful in communication with patients and affect decision outcomes, as is allowing nurses as well as physicians to adjust recommendations to fit the desires of patients gleaned from interactive discussions. ${ }^{[39]}$

Further studies among hospitalized patients utilizing larger samples sizes are recommended. Empirical testing of the CS exchange using framed messages (when patients are members of the DM within the interdisciplinary team) can provide a measurable intervention to determine if there is an impact on readmission. It can be inferred that when consistent CS use short phrases as framed messages, therapeutic interventions, readmission rates for PN can be reduced. The effectiveness of the process is based on the actions taken by the patients after hearing the framed messages. Framed messages, while promoting patient/families preferences on choices at the time of discharge, confirm existing knowledge. ${ }^{[32,35,39]}$ This study justifies considerations to educate RNs and CMs on the use of framed messages to engage patients in decisions in practice, as a therapeutic intervention to enhance readmission reduction. While increasing their knowledge on the value of improving the patients' involvement in decisions about care alternatives, in turn may improve patients' final outcomes and reduce the risk of readmission.

Finally, worldwide PN continues to be a prevalent concern among providers in many countries. ${ }^{[40,41]}$ Nationally in the U.S., hospital readmission for PN continues to be financially penalized. ${ }^{[1-3]}$ Nursing and hospital leadership must under- 
stand that within multifactorial transitions, CS may play a part in readmission reduction. ${ }^{[42,43]}$ Hospital administration, together with providers and nurses can actively involve patients with PN using framed messages, allowing patients to make better decisions at discharge. Readmission reduction results in both optimal patient health and significant hospital cost savings.

\section{Conflicts OF InTEREST Disclosure}

The authors declare they have no conflict of interest.

\section{REFERENCES}

[1] Centers for Medicare and Medicaid Services (CMS) (2011a). Federal Register. Hospital Recidivism Reduction Program. CMS Final Rule, Sec. 3025 of the Affordable Care Act. 2011 Aug 18; 76(160): 51476-51846.

[2] Centers for Medicare and Medicaid Services (CMS) (2011b). Medicare hospital quality chartbook performance report on readmissions. 2011 Sept 11. Available from: http://www.cms.gov/Medicare/Quality-Initiatives -Patient-AssessmentInstruments/HospitalQualityInit s/Downloads/HospitalChartBook2011.pdf

[3] Centers for Medicare and Medicaid Services (CMS). Readmission Reduction Program, $\$ 3025$ of the Affordable Care Act, Regulations 42 CFR part 412 ( $\$ 412$ through $\S 412.154$. Available from: http://www.cms.gov/Medicare/Medicare-Fee-for-Servi ce-Payment/AcuteInpatientPPS/Readmissions-Reducti on-Program.html

[4] Fung HB, Monteagudo-Chu MO. Community-acquired pneumonia in the elderly. Am J Geriatric Pharmacotherapy. 2010; 8(1): 47-62. PMid: 20226392. http://dx.doi.org/10.1016/j . amjopharm .2010 .01 .003

[5] Salovey P, Wegener DT. Social Psychological Foundations of Health and Illness. Chapter 3, Communicating about health: Message framing, persuasion and health behavior. Malden, Massachusetts: Blackwell Publishing; 2009.

[6] Young S. Oppenheimer DM. Effect of communication strategy on personal risk perception and treatment adherence intentions. Psy Health \& Med. 2009; 14(4): 430-442. PMid: 19697253. http: //dx.doi.org/10.1080/13548500902890103

[7] Groopman J, Hartzband P. Your medical mind, How to decide what is right for you. New York: Penguin Press; 2011.

[8] Health Research \& Educational Trust (HRET). Health care leader action guide to reduce avoidable readmissions. Repor Kim, S., Goldstein, D., Hasher, L., \& Zacks, R. T. Framing effects in younger and older adults. Journal of Gerontology and Psychological Sciences Social Sciences. 2005; 60(4): 215-218. American Hospital Association (AHA). The Commonwealth Fund and the John A. Hartford Foundation. 2010

[9] Schumacher KL, Meleis AK. Transitions: A central concept in nursing. IMAGE: J Nursing Scholarship. 1994; 26(2): 119-127. http: //dx.doi.org/10.1111/j.1547-5069.1994.tb00929.x

[10] Kahneman K. Thinking, Fast and Slow. $1^{\text {st }}$ ed. New York: Farrar, Straus \& Giroux; 2011. p 302, 304.

[11] Aujesky D, Fine MJ. The pneumonia severity index: A decade after the initial derivation and validation. Clinical Infectious Diseases. 2008; 47(Suppl_3): S133-139.

[12] Tversky A, Kahneman D. The framing of decisions and the psychology of choice. Science. 1981; 211(4481): 453-458. PMid: 7455683. http://dx.doi.org/10.1126/science. 7455683

[13] Mishra S, Gregson M, Lalumiere ML. Framing effects and risksensitive decision making. Brit J of Psy. 2012; 103(1): 83-97. PMid:
22229776. http://dx.doi.org/10.1111/j.2044-8295.2011 $.02047 . \mathrm{x}$

[14] Winter L, Parker B. Current health and preferences for life-prolong treatments: An application of prospect theory to end of life decision making. Soc Sci and Med. 2007; 65(8): 1695-1707. PMid: 17655996. http://dx.doi.org/10.1016/j.socscimed.2007.06.012

[15] Meleis AI. Theoretical nursing: Development and progress. $5^{\text {th }}$ ed. Philadelphia: Lippincott Williams \& Wilkins; 2012.

[16] Meleis AI. Transitions theory middle range and situation specific theories in nursing research and practice. New York: Springer; 2012

[17] Moxey A, O'Connell D, McGettigan P, et al. Describing treatment effects to patients. J Gen Int Med. 2003; 18(11): 948-959. http: //dx.doi.org/10.1046/j.1525-1497.2003.20928.x

[18] Naylor MD, Stephens C, Bowles KH, et al. Cognitively impaired older adults from hospital to home. Am J Nurs. 2005; 105(2): 52-61. PMid: 15674058. http://dx.doi.org/10.1097/00000446-2 00502000-00028

[19] Random.org. 2013. Available from: http://www.random.org/

[20] Nasreddine ZS, Phillips NA, Bedirian V, et al. The Montreal cognitive assessment, MOCA: A brief screening tool for mild cognitive impairment. J Am Geriatrics Soc. 2005; 53(4): 695-699. PMid: 15817019. http://dx.doi.org/10.1111/j.1532-5415.2005.53221.x

[21] Folstein MF, Folstein SE, McHugh PR. "Mini-mental state". A practical method for grading the cognitive state of patients for the clinician. Journal of Psychiatric Research. 1975; 12(3): 189-98. http://dx.doi.org/10.1016/0022-3956 (75) 90026-6

[22] Ware JE Jr, Sherbourne CD. The MOS 36-item short form health survey (SF-36). I. Conceptual framework and item selection. Medical Care. 1992; 30(6): 473-483. PMid: 1593914. http://dx.doi.org /10.1097/00005650-199206000-00002

[23] Arnold FW, Brock GN, Peyrani P, et al. Predictive accuracy of the pneumonia severity index vs. CRB-65 for time to clinical stability: Results from the community-acquired pneumonia organization (CAPO) international cohort study. Respiratory Med. 2010; 104(11): 1736-1743. PMid: 20576417. http://dx.doi.org/10.1016/j .rmed.2010.05.022

[24] Fine MJ, Auble TE, Yealy DM, et al. A prediction rule to identify low-risk patients with community-acquired pneumonia. N Engl J Med. 1997; 336(4): 243-250. PMid: 8995086. http://dx.doi.o rg/10.1056/NEJM199701233360402

[25] Bruce B, Fries JF. The Stanford health assessment questionnaire: Dimensions and practical applications. Health Quality Outcomes. 2003; 1(20): 1-6

[26] SAS. Version 9.2 of the SAS System for Microsoft Vista. 2014-2008. Available from: http://www.sas.com/en_us/legal/editoria l-guidelines.html

[27] Armonk. Statistical Package for Social Services (SPSS). Version 22.0 SPSS Statistics Standard Grad Pack 21, International Business Machines, IBM. 20122014. 
[28] Buchner A. G*Power. 2013. Available from: http: //www.psycho.uni-duesseldorf.de/abteilungen/aa $\mathrm{p} /$ gpower3/2013.pdf

[29] Naylor MD, Bowles KH, McCauley KM, et al. High-value transitional care: Transition of research into practice. Journal of Evaluation in Clinical Practice. 2011; 19(5): 727-733. PMid: 21410844.

[30] Naylor MD, Brooten D, Campbell R, et al. Comprehensive discharge planning and home follow-up of hospitalized elders: A randomized clinical trial. J Am Med Assoc. 1999; 281(7): 613-620. http://dx.doi.org/10.1001/jama.281.7.613

[31] Kim S, Goldstein D, Hasher L, et al. Framing effects in younger and older adults. The Journal of Gero. 2005; 60(4): 215-218. http://dx.doi.org/10.1093/geronb/60.4.P215

[32] Edwards A, Elwyn G. Understanding risk and lessons of clinical risk communication about treatment preferences. Quality Health Care. 2001; 10(Suppl I): 9-13. http://dx.doi.org/10.1136/qhc.0 100009

[33] Panidi K. Ostrich effects in health care decision theory and empirical evidence. 2014. Available from: http://icef.hse.ru/en/news/ 45093679.html

[34] Trupp RJ, Cowin EJ, Ahijevych KL, et al. The impact of educational message framing on adherence to continuous positive pressure therapy. Behavioral Sleep Med. 2011; 9(1): 38-52. http: //dx.doi.org/10.1080/15402002.2011.533993

[35] Goldberg LR, Koontz JS, Rogers N, et al. Considering accreditation in gerontology: The importance of interprofessional collaborative competencies to ensure quality health care for older adults. Gerontology \& Geriatrics Education. 2012; 33(1): 95-110. http://dx.doi.org/10.1080/02701960.2012.639101
[36] Kahneman D, Tversky A. Prospect theory: An analysis of decision under risk. Econometrica. 1979; 47(2): 263-291. http://dx.doi .org/10.2307/1914185

[37] Abellan JM, Bleichrodt H, Pinto-Prades JL. The predictive validity of prospect theory versus expected utility measurement. Journal of Health Economics. 2009; 28: 1039-1047. PMid: 19833400 http://dx.doi.org/10.1016/j.jhealeco.2009.09.002

[38] Braes T, Moons P, Lipkens P, et al. Screening for risk of unplanned readmission in older patients admitted to hospital: predictive accuracy of three instruments. Aging Clinical and Exp Research. 2009; 22(4): 345-351. http://dx.doi.org/10.1007/BF03324938

[39] Gandara E, Ungar J, Lee J, et al. Discharge documentation of patients discharged to subacute facilities: A three-year quality improvement process across an integrated health care system. Joint Commission Journal on Quality \& Patient Safety. 2010; 36(6): 243-251. PMid: 20564885.

[40] Metersky ML, Waterer G, Nsa W, et al. Predictors of in-hospital vs postdischarge mortality in pneumonia. Chest. 2012; 142(2): 476481. PMid: 22383662. http://dx.doi.org/10.1378/chest. 1 1-2393

[41] Angus DC, van der Poll T. Severe sepsis and septic shock. N Engl J Med. 2013; 369(21): 2063. http://dx.doi.org/10.1056/nej mra1208623

[42] Verma AA, Razak F, Detsky AS. Understanding choice: Why physicians should learn prospect theory. J Am Med Assoc. 2014;311(6): 571-572. PMid: 24519293. http://dx.doi.org/10.1001/jama. 2013. 285245

[43] Sox HC, Goodman SN. The methods of comparative effectiveness research. A Review of Public Health. 2012; 33: 425-445. PMid: 22224891. http://dx.doi.org/10.1146/annurev-pub lhealth-031811-124610 